\title{
Stereotactic radiosurgery for metastasis to the craniovertebral junction preserves spine stability and offers symptomatic relief
}

\author{
Tej D. Azad, BA, Rogelio Esparza, BA, Navjot Chaudhary, MD, and Steven D. Chang, MD \\ Department of Neurosurgery, Stanford University School of Medicine, Stanford, California
}

OBJECTIVE Metastatic disease to the craniovertebral junction (CVJ) is rare but presents unique management challenges. To date, studies on using stereotactic radiosurgery (SRS) for CVJ metastases have been limited to case reports and small case series. The aim of this analysis was to evaluate the utility of SRS in the management of these secondary lesions.

METHODS Clinical and radiological information from the charts of 25 patients with metastatic disease of the CVJ who were treated with SRS between 2005 and 2013 at the Stanford CyberKnife Center were retrospectively reviewed.

RESULTS Seven male and 18 female patients with a median age of 58 years (range 34-94 years) were identified. The most common primary tumors were breast cancer $(n=5)$ and non-small cell lung cancer $(n=5)$, and the most frequent symptom was neck pain $(n=17)$. The average tumor volume treated was $15.9 \mathrm{~cm}^{3}$ (range $\left.0.16-54.1 \mathrm{~cm}^{3}\right)$, with a mean marginal radiation dose of $20.3 \mathrm{~Gy}$ (range 15-25.5 Gy). The median follow-up was 18 months (range 1-81 months), though 1 patient was lost to follow-up.

SRS provided radiographic tumor stability in over $80 \%$ of patients, offered pain alleviation in nearly two-thirds of patients, and produced no serious complications. Moreover, SRS preserved spinal stability in all but 1 patient, in whom pre-SRS stability was established. There was no evidence of radiation toxicity in the patient population. Median survival was 28 months (range $2-81$ months), with survival of $13.3 \%$ at 5 years.

CONCLUSIONS In the absence of unstable pathological fracture and spinal cord compression, metastatic tumors of the CVJ can be safely and effectively treated with SRS. This treatment option offers palliative pain relief and can halt tumor progression with only a low risk of complications or spinal instability.

http://thejns.org/doi/abs/10.3171/2015.6.SPINE15190

KEY WORDS craniovertebral junction; metastasis; stereotactic radiosurgery; CyberKnife; oncology

$\mathrm{M}$ ETASTASIS to the craniovertebral junction (CVJ) is defined as the anatomical involvement of the occipital condyles and/or atlantoaxial spine. This occurrence is rare, accounting for $0.5 \%$ of all metastatic lesions to the spine. ${ }^{17}$ The primary tumors that most often seed the CVJ include breast carcinoma (35\%), non-small cell lung carcinoma (13\%), and prostate cancer $(10 \%) ., 2$
The mean age at presentation of upper cervical spine metastases is 60 years old. ${ }^{13}$ Patients with metastatic disease to this region often experience severe neck pain, which often requires operative or radiosurgical interventions in addition to medical management (Fig. 1).

Management is palliative and should strive to preserve spinal stability, optimize pain control, maintain neurolog-

ABBREVIATIONS CVJ = craniovertebral junction; NOMS = neurological, oncological, mechanical, and systemic; SINS = spinal instability neoplastic score; SRS = stereotactic radiosurgery.

SUBMITTED February 12, 2015. ACCEPTED June 3, 2015.

INCLUDE WHEN CITING Published online October 30, 2015; DOI: 10.3171/2015.6.SPINE15190. 

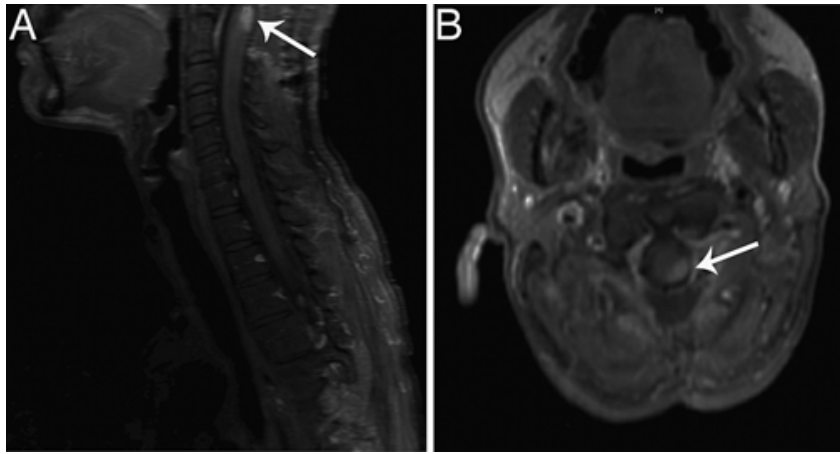

FIG. 1. Preoperative T1-weighted postcontrast sagittal (A) and axial (B) images. The lesion is indicated by the white arrow. The $0.64-\mathrm{cm}^{3}$ C2-level lesion in this patient was treated with $20 \mathrm{~Gy}$ in 2 fractions, and $96.3 \%$ coverage was achieved.

ical function, and achieve local tumor control. ${ }^{13}$ Open surgical management is indicated in patients with spine instability or patients who cannot receive radiation therapy due to previous radiation treatment fields overlapping the $\mathrm{CVJ}^{6}{ }^{6,19}$; however, open surgical management may be associated with substantial morbidity., 70,18

Stereotactic radiosurgery (SRS) has been demonstrated to improve local tumor control and lower complication rates in patients with spine metastatic disease relative to external beam radiotherapy and surgical resection (Fig. 2). 5,20 Though evidence specific to the CVJ is limited, small case series have yielded promising results. ${ }^{9,16,21}$ SRS at the CVJ is not without challenges, given the proximity of adjacent neurocritical structures including the brainstem, upper cervical spinal, and lower cranial nerves. We present the largest patient series, to our knowledge, of SRS for CVJ metastasis and demonstrate the role of this treatment modality in preserving spinal stability and alleviating pain.

\section{Methods \\ Cohort Creation}

Between 2005 and 2013, 25 patients with metastatic disease to the CVJ underwent SRS at the Stanford CyberKnife Center. Criteria for study inclusion were osseous metastatic lesions that involved the CVJ, which was defined as lower third of the clivus, occipital condyles, and C1-2 vertebrae. No patients who met these criteria were excluded. A retrospective review of these patients was undertaken by obtaining clinical and radiological information from an institutional review board-approved database. Data collected included patient demographics, date of diagnosis of spinal metastasis and its location, previous treatments (including chemo-, immuno-, and/or radiotherapy), preintervention pain (by subjective report), postintervention pain (by subjective report), preintervention spinal instability neoplastic score (SINS), ${ }^{3}$ total SRS dose (Gy) and fractions administered to the CVJ, postintervention radiographic occurrence of deformity or compression fracture, and need for further surgery at the spinal SRS index level.
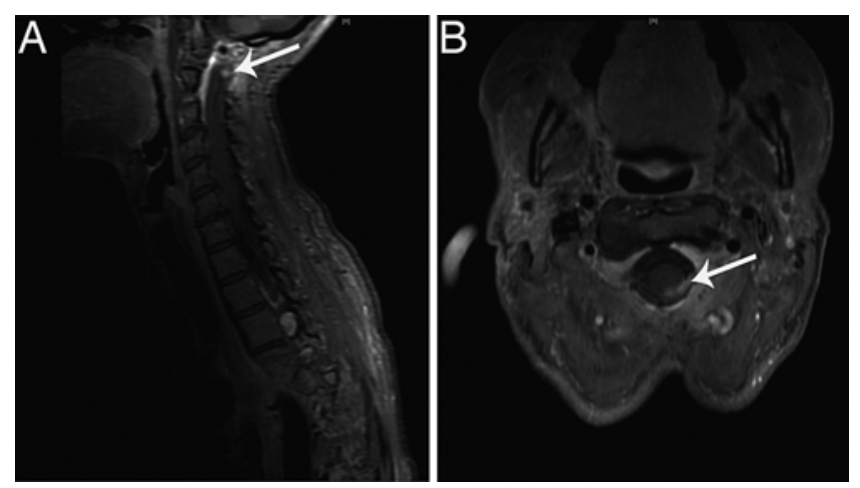

FIG. 2. Postoperative T1-weighted postcontrast sagittal (A) and axial (B) images. The remaining lesion is indicated by the white arrow.

\section{Image-Guided Radiosurgery Treatment}

Image-guided radiosurgery in the form of the $\mathrm{Cy}$ berKnife was used throughout this study. All patients underwent immobilization in a noninvasive head restraint, such as the molded Aquaplast mask (WFR/Aquaplast) during cranial treatments or a custom alpha cradle mold (Smithers Medical Products) during spinal treatments.

Thin-slice contrast-enhanced CT scans $(1.25 \mathrm{~mm})$ and MRI $(2.0 \mathrm{~mm})$ scans were obtained, loaded onto the treatment planning computer, and fused. Tumor tracking was provided by the Xsight spine tracking system (Accuray). Dose constraints for single and hypofractioned regimens were determined based on the guidelines defined by the American Association of Physicists in Medicine Task Group 101. For single fractions to the cord and esophagus, the constraints were 10 Gy and $11.9 \mathrm{~Gy}$, respectively. For 3 fractions to the cord and esophagus, the constraints were $18 \mathrm{~Gy}$ and $17.7 \mathrm{~Gy}$, respectively. For 5 fractions to the cord and esophagus, the constraints were $23 \mathrm{~Gy}$ and $19.5 \mathrm{~Gy}$, respectively. ${ }^{1}$

\section{Follow-Up}

Median follow-up was 18 months (range 1-81 months), though 1 patient was lost to follow-up. Patients underwent clinical follow-up at 3 months and 6 months posttreatment and then every 6 months for the first 2 years, though this was not possible for all patients due to death among the patients with metastatic disease. Images with a minimum of 3.5-mm slice thickness were obtained, and tumor size was calculated by measuring along the 3 axes to provide a volumetric figure. Any net decrease along 1 or more of the axes by $3 \mathrm{~mm}$ was recorded as tumor reduction. Likewise, a net increase of $3 \mathrm{~mm}$ in any of the dimensions was considered to indicate tumor growth. Follow-up images were also assessed for evidence of radiation necrosis.

\section{Results}

\section{Cohort Characteristics}

Our retrospective review yielded 7 male and 18 female patients with a median age of 58 years (range 34-94 years). The most common primary lesions were breast cancer $(n=5)$ and non-small cell lung cancer $(n=5)$. The 
TABLE 1. Clinical overview of patients with metastases to the CVJ

\begin{tabular}{|c|c|c|c|c|c|c|}
\hline Case No. & $\begin{array}{c}\text { Age at SRS } \\
(y r s)\end{array}$ & Sex & Primary Tumor & Symptoms at Presentation & $\begin{array}{c}\text { Follow-Up* } \\
\text { (mos) }\end{array}$ & $\begin{array}{c}\text { Tumor } \\
\text { Locationt }\end{array}$ \\
\hline 1 & 56 & $\mathrm{~F}$ & Mediastinal teratoma & Constipation, incontinence & 54 & D \\
\hline 2 & 43 & $\mathrm{~F}$ & Parotid acinic cell carcinoma & Neck pain, CN palsy & 42 & V \\
\hline 3 & 58 & $\mathrm{~F}$ & NSCLC & Neck pain & 38 & D \\
\hline 4 & 59 & $\mathrm{~F}$ & NSCLC & Neck pain, weight loss & 16 & V \\
\hline 5 & 51 & M & Melanoma & Neck pain & 28 & $\mathrm{D}$ \\
\hline 6 & 49 & $\mathrm{~F}$ & Breast cancer & NR & 2 & B \\
\hline 7 & 69 & $\mathrm{M}$ & Prostate cancer & Neck pain & 2 & V \\
\hline 8 & 69 & $\mathrm{~F}$ & NSCLC & Neck pain & 18 & V \\
\hline 9 & 74 & M & Lung adenocarcinoma & Neck pain & 16 & V \\
\hline 10 & 94 & $\mathrm{~F}$ & Merkel cell carcinoma & Neck pain & 39 & V \\
\hline 11 & 65 & M & Prostate cancer & Neck pain & 48 & V \\
\hline 12 & 69 & $\mathrm{~F}$ & Lingula adenocarcinoma & NR & 44 & $B$ \\
\hline 13 & 58 & $\mathrm{~F}$ & Breast cancer & Neck pain, CN palsy & 81 & V \\
\hline 14 & 58 & $\mathrm{~F}$ & NSCLC & Neck pain & 8 & V \\
\hline 15 & 52 & $\mathrm{~F}$ & Ovarian cancer & NR & 75 & V \\
\hline 16 & 52 & $\mathrm{~F}$ & Breast cancer & CN palsy & 36 & V \\
\hline 17 & 81 & $\mathrm{~F}$ & Breast cancer & Neck pain & 18 & $B$ \\
\hline 18 & 70 & M & Renal cell carcinoma & NR & 16 & D \\
\hline 19 & 52 & $\mathrm{~F}$ & Colorectal cancer & Neck pain & 5 & $B$ \\
\hline 20 & 57 & $\mathrm{~F}$ & Colorectal cancer & Neck pain, hand tremor & 0 & V \\
\hline 21 & 62 & $\mathrm{~F}$ & Liposarcoma & Neck pain, CN palsy & 36 & B \\
\hline 22 & 72 & $M$ & Prostate cancer & Neck pain & 3 & B \\
\hline 23 & 52 & M & Breast cancer & NR & NR & V \\
\hline 24 & 34 & $\mathrm{~F}$ & NSCLC & L-5 radiculopathy & 7 & V \\
\hline 25 & 38 & $\mathrm{~F}$ & Gastric carcinoma & Neck pain & 1 & $B$ \\
\hline
\end{tabular}

most frequent symptom was neck pain $(\mathrm{n}=17)$, followed by cranial nerve palsy $(n=4)$. Other presenting symptoms included constipation, urinary incontinence, weight loss, hand tremor, and lumbar radiculopathy (Table 1).

All but 1 patient had some form of prior treatment for the primary tumor. However, no patient received radiation therapy or resection for the CVJ metastasis prior to SRS.

\section{Radiosurgical Treatment}

Among the 25 lesions, 1 lesion received 5 fractions, 7 lesions received 3 fractions, 5 lesions received 2 fractions, and 12 lesions received a single fraction. The number of fractions delivered was determined by discussion between the neurosurgeon and radiation oncologist and based on the patient and lesion characteristics, chiefly tumor size and anatomical location. Critical structures were contoured to limit the radiation dose to these structures.

Treatment plans were personalized for each patient based on tumor size, location, isodose coverage, and tissue doses. The average tumor volume treated was $15.9 \mathrm{~cm}^{3}$ (range $0.16-54.1 \mathrm{~cm}^{3}$ ), with a mean marginal radiation dose of $20.3 \mathrm{~Gy}$ (range 15-25.5 Gy) and a mean maximum intratumoral dose of 26.4 Gy (range 20.3-35.7 Gy). The mean number of isocenters was 141.7, the mean conformality index was 1.46 , and the mean percentage of coverage was $94.4 \%$ (Table 2). In this cohort, we did not note any toxicity related to SRS.

\section{Preoperative Spine Stability}

Preintervention SINS was calculated for all 25 treated lesions. The mean SINS was 7.3 (range 3-12). Nine lesions were classified as stable (SINS 0-6), and 15 lesions were classified as indeterminate (SINS 7-12). No lesions were classified as unstable. Because our cohort includes patients selected for spinal SRS, it is comprehensible that no analyzed lesions qualified as frankly unstable per the SINS criteria, as such lesions are more appropriate for surgical intervention.

\section{Postoperative Outcome}

In our series, only 2 patients required post-SRS sur- 
TABLE 2. CyberKnife radiosurgery dosimetry for the treatment of CVJ metastases

\begin{tabular}{|c|c|c|c|c|c|c|c|c|c|}
\hline Case No. & $\begin{array}{c}\text { Lesion } \\
\text { Volume (ml) }\end{array}$ & Fractions & $\begin{array}{l}\text { Rx Dose } \\
\text { (Gy) }\end{array}$ & $\begin{array}{l}\text { Maximum } \\
\text { Dose (Gy) }\end{array}$ & $\begin{array}{c}\text { Biological } \\
\text { Equivalent } \\
\text { Dose }\left(\mathrm{Gy}_{10}\right)\end{array}$ & Level of SRS & $\begin{array}{c}\text { No. of } \\
\text { Isocenters }\end{array}$ & $\begin{array}{l}\text { Conformality } \\
\text { Index }\end{array}$ & Coverage $(\%)$ \\
\hline 1 & 0.64 & 2 & 20 & 26.7 & 40 & C1-2 & 106 & 1.49 & 96.3 \\
\hline 2 & 6.47 & 2 & 20 & 25.0 & 40 & C1 & 117 & 1.60 & 96 \\
\hline 3 & 41.54 & 3 & 24 & 28.9 & 43.2 & $C 1-3$ & 138 & 1.38 & 90.2 \\
\hline 4 & 30.92 & 3 & 24 & 29.3 & 43.2 & C1-2 & 142 & 1.44 & 91.1 \\
\hline 5 & 0.77 & 1 & 24 & 30.0 & 81.6 & C1 & 103 & 1.67 & 95.7 \\
\hline 6 & 10.10 & 3 & 21 & 25.9 & 35.7 & C1 & 130 & 1.47 & 98.4 \\
\hline 7 & 54.07 & 2 & 20 & 26.7 & 40 & C1-2 & 223 & 1.37 & 94.7 \\
\hline 8 & 12.11 & 1 & 18 & 22.8 & 50.4 & C1 & 166 & 1.75 & 94.2 \\
\hline 9 & 21.81 & 1 & 18 & 22.5 & 50.4 & C1-2 & 189 & 1.76 & 95.5 \\
\hline 10 & 19.98 & 3 & 24 & 30.0 & 43.2 & C1 & 196 & 1.70 & 99.7 \\
\hline 11 & 11.25 & 1 & 16 & 21.9 & 41.6 & $\mathrm{C1}$ & 142 & 1.29 & 98.3 \\
\hline 12 & 5.08 & 1 & 19 & 23.2 & 55.1 & C1 & 100 & 1.21 & 94.9 \\
\hline 13 & 21.98 & 1 & 15 & 20.3 & 37.5 & $\mathrm{C1}$ & $N R$ & 1.41 & 94.7 \\
\hline 14 & 1.66 & 2 & 20 & 24.7 & 40 & C1-2 & 184 & 1.51 & 98.4 \\
\hline 15 & 1.49 & 5 & 25 & 35.7 & 37.5 & C1 & 147 & 1.35 & 91.5 \\
\hline 16 & 9.66 & 1 & 16 & 22.9 & 41.6 & $\mathrm{C} 2$ & 119 & 1.11 & 90.8 \\
\hline 17 & 17.06 & 1 & 16 & 21.1 & 41.6 & $\mathrm{C} 2$ & 128 & NR & 92.1 \\
\hline 18 & 0.16 & 1 & 18 & 21.7 & 50.4 & C2-3 & 163 & 1.64 & 83.3 \\
\hline 19 & 10.80 & 1 & 20 & 25.3 & 60 & $\mathrm{C} 2$ & 139 & 1.53 & 91.6 \\
\hline 20 & 7.35 & 1 & 18 & 23.7 & 50.4 & $\mathrm{C} 2$ & 103 & 1.39 & 95.7 \\
\hline 21 & 28.10 & 3 & 24 & 32.0 & 43.2 & C1-2 & 123 & 1.37 & NR \\
\hline 22 & 35.15 & 3 & 24 & 34.3 & 43.2 & $\mathrm{C} 2$ & 140 & 1.28 & 94.4 \\
\hline 23 & 15.63 & 2 & 20 & 27.4 & 40 & $\mathrm{C1}$ & 109 & 1.43 & 97.4 \\
\hline 24 & 3.78 & 1 & 18 & 24.3 & 50.4 & $\mathrm{C} 2$ & 145 & 1.46 & 95.9 \\
\hline 25 & 29.00 & 3 & 25.5 & 34.5 & 47.18 & C2-3 & 148 & 1.41 & 94.6 \\
\hline
\end{tabular}

$\mathrm{Rx}=$ radiation .

gery to stabilize the cervical spine. The first patient had documented pre-SRS spinal instability, but this patient was deemed a poor candidate for surgery due to chronic obstructive pulmonary disease exacerbations. Following SRS, the patient required laminectomy with tumor resection and posterior cervical arthrodesis from the occiput to the C-6 level. The second patient developed a pathological fracture with collapse of the C-2 vertebral body following initial SRS, underwent spinal fusion from the occiput to the C-6 level, and eventually received a second SRS which resulted in tumor regression and further symptomatic relief.

Of the patients who reported neck pain $(\mathrm{n}=17)$, marked decrease or full resolution was observed in 8 patients, no change was reported in 5 patients, and changes in pain were not reported in 4 patients. Cranial nerve palsy improved in 3 of the 4 patients who presented with this symptom. Following SRS, lesion size was radiographically determined at the most recent follow-up in 19 patients and found to be decreased in 4 patients, unchanged in 12 patients, and increased in 3 patients. There was no evidence of radiation toxicity in our patient population. Median survival was 28 months (range 2-81 months), and the overall Kaplan-Meier survival at 3 years following SRS was $46.7 \%$ (Table 3; Fig. 3).

\section{Discussion}

Patients with metastatic disease to the CVJ had a median survival of nearly 3 years in our study (Table 4). This underscores the importance of optimizing the quality of life of these patients. In our study of 25 patients with metastases to the CVJ, SRS provided radiographic tumor stability in over $80 \%$ of patients, offered pain alleviation in over $60 \%$ of patients, and produced no serious complications. Moreover, we found that SRS preserved spinal stability in all but 1 patient, in whom pre-SRS stability was established.

A number of predictors of survival following spinal metastatic disease have been indicated in previous studies, including pain at presentation ${ }^{11}$ and local progression after SRS..$^{14}$ In our analysis, these indicators showed no significant influence on survival or symptomatic resolution. Moreover, we found no significant association between preoperative spinal instability (as determined by SINS) and patient outcome following initial patient selection for 
TABLE 3. Postoperative outcomes for patients undergoing SRS for CVJ metastasis

\begin{tabular}{|c|c|c|c|c|c|c|}
\hline Case No. & Survival (mos) & $\begin{array}{c}\text { CN Palsy } \\
\text { Improvement }\end{array}$ & $\begin{array}{c}\text { Pain } \\
\text { Improvement }\end{array}$ & $\begin{array}{c}\text { Pathological } \\
\text { Fracture }\end{array}$ & Spine Surgery & Change in Lesion Size \\
\hline 1 & 54 & NA & NA & No & No & Decreased \\
\hline 2 & 42 & Yes & Yes & No & No & Decreased \\
\hline 3 & 38 & NA & No & No & Yes & Unchanged \\
\hline 4 & 16 & NA & Yes & No & No & Unchanged \\
\hline 5 & 28 & NA & No & No & No & Unchanged \\
\hline 6 & 2 & NA & NA & No & No & Unchanged \\
\hline 7 & 2 & NA & NR & No & No & NR \\
\hline 8 & 18 & NA & Yes & No & No & Unchanged \\
\hline 9 & 16 & NA & Yes & No & No & Unchanged \\
\hline 10 & NR & NA & Yes & No & No & Increased \\
\hline 11 & 48 & NA & NR & No & No & NR \\
\hline 12 & 44 & NA & NA & No & No & Unchanged \\
\hline 13 & 81 & No & Yes & No & No & Unchanged \\
\hline 14 & NR & NA & No & No & No & Increased \\
\hline 15 & 75 & NA & NA & No & No & NR \\
\hline 16 & NR & Yes & NA & No & No & Unchanged \\
\hline 17 & NR & NA & Yes & No & No & Unchanged \\
\hline 18 & NR & NA & NA & No & No & Decreased \\
\hline 19 & 5 & NA & Yes & No & No & Increased \\
\hline 20 & NR & NA & NR & No & No & NR \\
\hline 21 & NR & Yes & No & Yes & Yes & Decreased \\
\hline 22 & NR & NA & No & No & No & Unchanged \\
\hline 23 & NR & NA & NA & NR & No & NR \\
\hline 24 & 7 & NA & NA & No & No & Unchanged \\
\hline 25 & NR & NA & NR & No & NR & NR \\
\hline
\end{tabular}

NA = not applicable.

SRS. The neurological, oncological, mechanical, and systemic (NOMS) framework suggests that the histology of the primary tumor can influence the radiation susceptibility of the tumors to external-beam radiation therapy, but posits that responses to SRS are largely independent of primary tumor histology. ${ }^{12}$ Thus, our findings agree with the NOMS framework, in that we found no notable difference in outcomes between the lesions of different histological origins.

Metastatic disease of the CVJ poses a therapeutic challenge given the mechanical and neuroanatomical complexity of the region; open surgery and SRS are possible management options that could help avoid or alleviate issues of pain or structural instability. Surgical resection is a valuable option to address unstable fractures and symptomatic brainstem or spinal cord compression. ${ }^{2}$ However, the efficacy of open surgery can vary with tumor pathology, anatomical location, and surgical approach., ${ }^{7,15}$ Fusion of the CVJ reduces the occipitocervical range of motion and can increase the risk of dural laceration, dysphagia, vertebral artery injury, and neurological injury. ${ }^{10}$

SRS can be considered a viable alternative to open surgery for metastatic disease to the stable CVJ. Recently, Tuchman et al. presented a series of 9 patients with 10
CVJ tumors. ${ }^{21}$ The most frequent diagnosis was hepatocellular carcinoma $(n=4)$, and the median lesion volume was $9.66 \mathrm{~cm}^{3}$. The most common presenting symptom was headache or neck pain $(n=6)$. The median dose for patients receiving Gamma Knife radiosurgery $(n=2)$ was $17 \mathrm{~Gy}$, and the median survival was 4 months (range 1-51 months) for patients receiving $20.5 \mathrm{~Gy}(\mathrm{n}=7)$. Five of the 6 patients who presented with pain had improvement in their symptoms after treatment, and CVJ instability requiring surgical stabilization was not noted either before or after SRS in any patient. ${ }^{21}$ Our results are consistent with the findings of Tuchman et al. and strengthen the case for administering SRS to patients with metastatic disease to the CVJ.

Our study is not without limitations. Given the wide geographic distribution of patients referred to Stanford Hospital and Clinics, comprehensive follow-up was not available for all patients. However, follow-up was available for the majority of patients in all reported outcomes. Furthermore, neck pain was not measured through the use of a visual analog scale. Our study derived information regarding pain alleviation from the subjective patient reports in the medical charts, in which neck pain was either expressed as a categorical variable (e.g., yes, no, or same) 


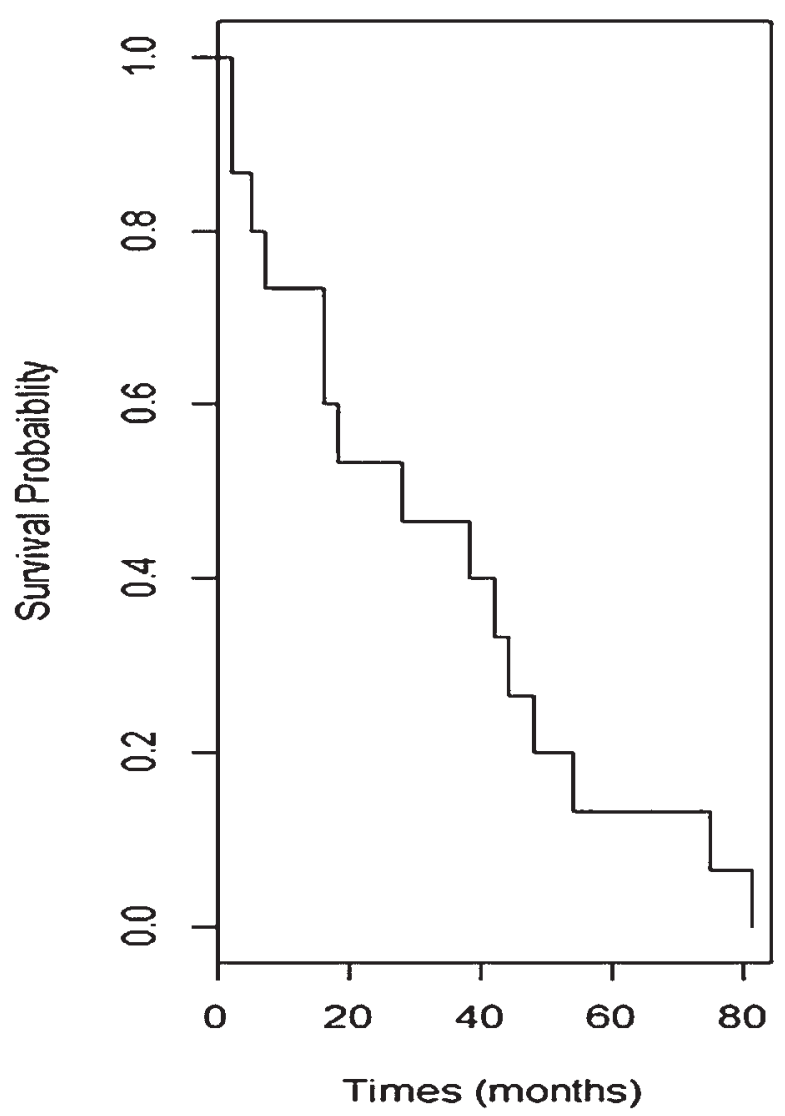

\begin{tabular}{|c|c|c|c|c|c|}
\hline Time (months) & 0 & 20 & 40 & 60 & 80 \\
\hline Patients Surviving (N) & 15 & 8 & 6 & 2 & 1 \\
\hline
\end{tabular}

FIG. 3. Kaplan-Meier survival curve following SRS for CVJ metastatic lesion.

or as an integer (1-10) using the comparative pain scale. Although these limitations are important to note, we believe our findings, when contextualized with previous reports and case series, demonstrate the value of SRS in the management of metastatic lesions to the CVJ.

TABLE 4. Characteristics of patients with CVJ metastases treated with SRS

\begin{tabular}{lc}
\hline \multicolumn{1}{c}{ Characteristic } & Value \\
\hline No. of patients & 25 \\
\hline No. of females, $\mathrm{n}(\%)$ & $18(72.0)$ \\
\hline Median age, $\mathrm{yrs}($ range) & $58(34-94)$ \\
\hline Median survival, mos (range) & $28(2-81)$ \\
\hline Mean tumor volume, $\mathrm{cm}^{3}$ (range) & $15.9(0.2-54.1)$ \\
\hline Mean marginal dose, Gy (range) & $20.3(15-25.5)$ \\
\hline No. of patients with tumor reduction, $\mathrm{n}(\%)$ & $4(21.0)$ \\
\hline No. of patients with stable tumor, $\mathrm{n}(\%)$ & $12(63.2)$ \\
\hline No. of patients with pain reduction, $\mathrm{n}(\%)$ & $8(61.5)$ \\
\hline No. of patients with post-SRS spine surgery, $\mathrm{n}(\%)$ & $2(8.0)$ \\
\hline
\end{tabular}

\section{Conclusions}

To our knowledge, this is the largest sample of patients with metastatic disease of the CVJ treated with SRS. In the absence of unstable pathologic fracture and spinal cord compression, metastatic tumors of the CVJ can be safely and effectively treated with SRS. This treatment option offers palliative pain relief and halts tumor progression with only a low risk of complications or spinal instability.

\section{References}

1. Benedict SH, Yenice KM, Followill D, Galvin JM, Hinson W, Kavanagh B, et al: Stereotactic body radiation therapy: the report of AAPM Task Group 101. Med Phys 37:4078-4101, 2010 (Erratum in Med Phys 39:563, 2012)

2. Bilsky MH, Shannon FJ, Sheppard S, Prabhu V, Boland PJ: Diagnosis and management of a metastatic tumor in the atlantoaxial spine. Spine (Phila Pa 1976) 27:1062-1069, 2002

3. Fourney DR, Frangou EM, Ryken TC, Dipaola CP, Shaffrey CI, Berven SH, et al: Spinal instability neoplastic score: an analysis of reliability and validity from the spine oncology study group. J Clin Oncol 29:3072-3077, 2011

4. Fourney DR, York JE, Cohen ZR, Suki D, Rhines LD, Gokaslan ZL: Management of atlantoaxial metastases with posterior occipitocervical stabilization. J Neurosurg 98 (2 Suppl):165-170, 2003

5. Hall WA, Stapleford LJ, Hadjipanayis CG, Curran WJ, Crocker I, Shu HK: Stereotactic body radiosurgery for spinal metastatic disease: an evidence-based review. Int J Surg Oncol 2011:979214, 2011

6. Hastings DE, Macnab I, Lawson V: Neoplasms of the atlas and axis. Can J Surg 11:290-296, 1968

7. Jones DC, Hayter JP, Vaughan ED, Findlay GF: Oropharyngeal morbidity following transoral approaches to the upper cervical spine. Int J Oral Maxillofac Surg 27:295-298, 1998

8. Karam YR, Menezes AH, Traynelis VC: Posterolateral approaches to the craniovertebral junction. Neurosurgery 66 (3 Suppl):135-140, 2010

9. Krishnamurthy S, Navarro-Martín A, Maitz A: Gamma Knife radiosurgery for occipital condyle metastasis. Clin Transl Oncol 11:622-624, 2009

10. Lall R, Patel NJ, Resnick DK: A review of complications associated with craniocervical fusion surgery. Neurosurgery 67:1396-1403, 2010

11. Lau D, Leach MR, La Marca F, Park P: Independent predictors of survival and the impact of repeat surgery in patients undergoing surgical treatment of spinal metastasis. J Neurosurg Spine 17:565-576, 2012

12. Laufer I, Rubin DG, Lis E, Cox BW, Stubblefield MD, Yamada Y, et al: The NOMS framework: approach to the treatment of spinal metastatic tumors. Oncologist 18:744751,2013

13. Moulding HD, Bilsky MH: Metastases to the craniovertebral junction. Neurosurgery 66 (3 Suppl):113-118, 2010

14. Sellin JN, Reichardt W, Bishop AJ, Suki D, Rhines LD, Settle SH, et al: Factors affecting survival in 37 consecutive patients undergoing de novo stereotactic radiosurgery for contiguous sites of vertebral body metastasis from renal cell carcinoma. J Neurosurg Spine 22:52-59, 2015

15. Sen C, Shrivastava R, Anwar S, Triana A: Lateral transcondylar approach for tumors at the anterior aspect of the craniovertebral junction. Neurosurgery 66 (3 Suppl):104-112, 2010 
16. Sheehan JP, Shaffrey CI, Schlesinger D, Williams BJ, Arlet V, Larner J: Radiosurgery in the treatment of spinal metastases: tumor control, survival, and quality of life after helical tomotherapy. Neurosurgery 65:1052-1062, 2009

17. Sherk HH: Lesions of the atlas and axis. Clin Orthop Relat Res (109):33-41, 1975

18. Shin H, Barrenechea IJ, Lesser J, Sen C, Perin NI: Occipitocervical fusion after resection of craniovertebral junction tumors. J Neurosurg Spine 4:137-144, 2006

19. Sundaresan N, Galicich JH, Lane JM, Greenberg HS: Treatment of odontoid fractures in cancer patients. J Neurosurg 54:187-192, 1981

20. Timmerman RD, Bizekis CS, Pass HI, Fong Y, Dupuy DE, Dawson LA, et al: Local surgical, ablative, and radiation treatment of metastases. CA Cancer J Clin 59:145-170, 2009

21. Tuchman A, Yu C, Chang EL, Kim PE, Rusch MC, Apuzzo ML: Radiosurgery for metastatic disease at the craniocervical junction. World Neurosurg 82:1331-1336, 2014

\section{Disclosure}

The authors report no conflict of interest concerning the materials or methods used in this study or the findings specified in this paper.

\section{Author Contributions}

Conception and design: all authors. Acquisition of data: Azad, Esparza. Analysis and interpretation of data: Azad, Esparza. Drafting the article: all authors. Critically revising the article: Chang, Azad, Chaudhary. Statistical analysis: Azad. Administrative/technical/material support: Chang, Chaudhary. Study supervision: Chang, Chaudhary.

\section{Correspondence}

Steven D. Chang, Department of Neurosurgery, Stanford University School of Medicine, 200 Pasteur Dr., Stanford, CA 94305. email: sdchang@stanford.edu. 